\title{
Diffuse primary B-cell lymphoma of large B-cell, leg-type. A case report
}

\section{Beatriz Di Martino Ortiz, Rosalba Riveros, Lourdes Rodríguez, Silvia Aguilar, Mirtha Rodríguez, Oilda Knopfelmacher, Lourdes Bolla}

Dermatology Department, Clinicas Hospital, Faculty of Medical Sciences, National University of Ausunción-Paraguay

Corresponding author: Prof. Dra. Beatriz Di Martino Ortiz, E-mail: beatrizdimartino@gmail.com

\begin{abstract}
SUMMARY
B-cell cutaneous lymphomas are a heterogeneous group of lymphomas that appear on skin with no evidence of extracutaneous involvement at the time of diagnosis and correspond between $20 \%$ and $25 \%$ of primary cutaneous lymphomas. We present a case of diffuse primary B-cell lymphoma of large B-cell, diagnosed with clinical and pathological anatomy, typified by immunohistochemistry in an 87-year-old patient with multiple baseline pathologies, polymedicated, with good cutaneous response to treatment.
\end{abstract}

Key words: Cutaneous B-cell; Leg-type; Diffuse 


\title{
Linfoma B cutáneo primario difuso de células grandes, tipo pierna. Reporte de un caso
}

\section{Beatriz Di Martino Ortiz, Rosalba Riveros, Lourdes Rodríguez, Silvia Aguilar, Mirtha Rodríguez, Oilda Knopfelmacher, Lourdes Bolla}

\author{
Dermatology Department, Clinicas Hospital, Faculty of Medical Sciences, National University of Ausunción-Paraguay
}

Corresponding author: Prof. Dra. Beatriz Di Martino Ortiz, E-mail: beatrizdimartino@gmail.com

\begin{abstract}
RESUMEN
Los linfomas cutáneos de células B son un grupo heterogéneo de linfomas que se presentan en piel sin evidencia de compromiso extracutáneo al momento del diagnóstico y corresponden entre 20\% al 25\% de los linfomas cutáneos primarios. Presentamos un caso de un linfoma primario cutáneo difuso de células B grandes, tipo pierna, diagnosticado con la clínica y anatomía patológica, tipificado por la inmunohistoquímica en un paciente de 87 años con múltiples patologías de base, polimedicado, con buena respuesta cutánea al tratamiento instaurado.
\end{abstract}

Palabras clave: Línfoma cutáneo de células B; Tipo pierna; Difuso

\section{INTRODUCCIÓN}

Los linfomas cutáneos primarios de células B son un grupo heterogéneo de neoplasias linfoides de curso clínico indolente que tienden a permanecer localizados en la piel y sólo en raras ocasiones presentan una diseminación extracutánea.

Como grupo, los linfomas cutáneos primarios de células $\mathrm{B}$ presentan un mejor pronóstico que los de células T.

Una evaluación correcta de los pacientes en los que se sospeche la presencia de un linfoma cutáneo de células B requiere la correlación adecuada de la información clínica, los hallazgos histopatológicos e inmunofenotípicos y los datos de biología molecular. El diagnóstico definitivo, además, debe tener en cuenta el subtipo específico según las clasificaciones actuales de los linfomas.

El tratamiento inicial suele ser conservador, bien mediante exéresis quirúrgica, si es factible, o mediante radioterapia convencional localizada para las lesiones primarias de mayor tamaño o en caso de recurrencias. Sólo se recomienda tratamiento poliquimioterápico para los pacientes con una enfermedad cutánea extensa, en aquellas formas o subtipos que se consideran de curso agresivo o en casos con afectación extracutánea y, a menudo, en combinación con radioterapia local.

\section{CASO CLÍNICO}

Varón, 87 años, paraguayo, casado, jubilado, procedente de medio urbano, consulta por una lesión sobre elevada rojiza tipo picadura de insecto en pierna derecha de 9 meses de evolución, con aumento progresivo de tamaño, y sensación de hormigueo. Consultó con facultativo quién indica ATB VO y tópicos (betametasona tópica y cremas hidratantes), sin mejoría. Hace 2 meses aparecen más lesiones de gran tamaño, abarcando toda la pierna derecha, algunas drenan secreción serohemática. Se realiza curaciones con iodopovidona, con empeoramiento de las lesiones.

Hace 1 mes lesión sobre elevada roja en mentón con aumento progresivo de tamaño y número. Recibe cefalexina, AINES, ácido fusídico + betametasona, sin mejoría, por lo que acude a nuestro servicio.

Pérdida de $10 \mathrm{Kg}$ desde el inicio del cuadro. 


\section{Antecedentes patológicos personales}

HTA, Enfermedad de Parkinson, Cirugía de próstata hace 20 años por Carcinoma de próstata, Cardiopatía isquémica con marcapasos, Ex tabaquista, Antecedente de Neumotórax por rotura de bulla. En tratamiento actual con: Losartan $50 \mathrm{mg} / 50 \mathrm{mg}$, Amlodipina $10 \mathrm{mg} / \mathrm{d}$, Memantina $10 \mathrm{mg} / 10 \mathrm{mg}$, Alprazolam 0,5 mg/d, Quetiapina 100mg/d, Donepecilo 10mg/d, Tamsulosina $0,4 \mathrm{mg} / \mathrm{d}$.

\section{Antecedentes patológicos familiares}

Madre fallecida por Cáncer de colon.

\section{Examen físico}

- Placa hiperpigmentada de bordes irregulares, límites netos, que abarca toda la circunferencia de la pierna derecha, con áreas hipopigmentadas y descamativas en extremo distal, sobre la que asientan múltiples tumores eritematovioláceos redondeados bien delimitados de consistencia sólida elástica de cuyos diámetros oscilan de 5 a 40 mm (Fig. 1).

- La mayor de aproximadamente $40 \mathrm{~mm}$ de diámetro en tercio inferior cara anterior de pierna derecha, friable y con costras hemáticas. Hiperqueratosis plantar y subungueal de primer dedo de pie derecho (Fig. 2).

- Tumoración eritematosa redondeada de bordes regulares límites netos de consistencia sólida dura de $1 \mathrm{~cm}$ de diámetro en mentón lado derecho y otra de iguales características de $1,5 \mathrm{~cm}$ en región infra

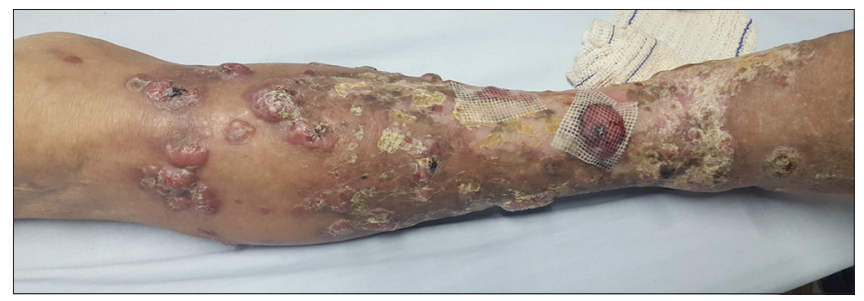

Figure 1: Clinic. Multiple erythemato violaceous tumors that settle in the lower third of the anterior face of the right leg.

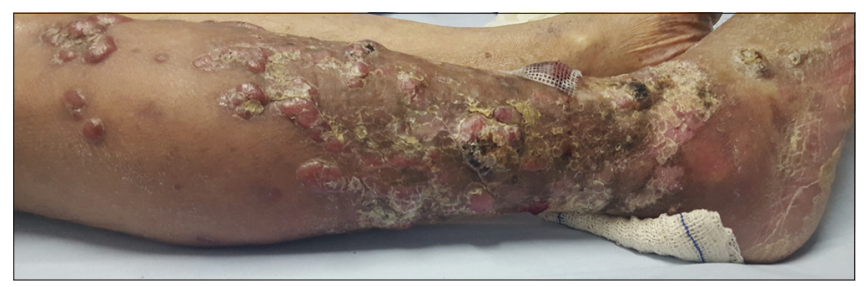

Figure 2: Clínic. Multiple well-demarcated rounded erythematous violaceous tumors of solid elastic consistency, between 5 and $40 \mathrm{~mm}$ in right leg. Plantar and subungual hyperkeratosis of the right first toe. labial izquierda (Fig. 3).

- Paciente caquéctico, sin adenomegalias ni otras lesiones en piel.

Se toma biopsia de una de las lesiones nodulares de la pierna, la cual muestra epidermis preservada y proceso neoplásico asentado en dermis superficial y media de crecimiento difuso. Ausencia de afectación epidérmica o epidermotropismo. La proliferación celular observada es de estirpe linfoide y crecimiento difuso (Fig. 4).

A mayor aumento observamos que se trata de una proliferación linfoide atípica constituida por células grandes con núcleos vesiculares, uno o más nucléolos evidentes y citoplasma escaso a moderado. Crecen en forma difusa desde la dermis papilar a la reticular profunda. En áreas adoptan un patrón nodular. Se ven escasos linfocitos pequeños mezclados. El índice mitótico es alto (Fig. 5).

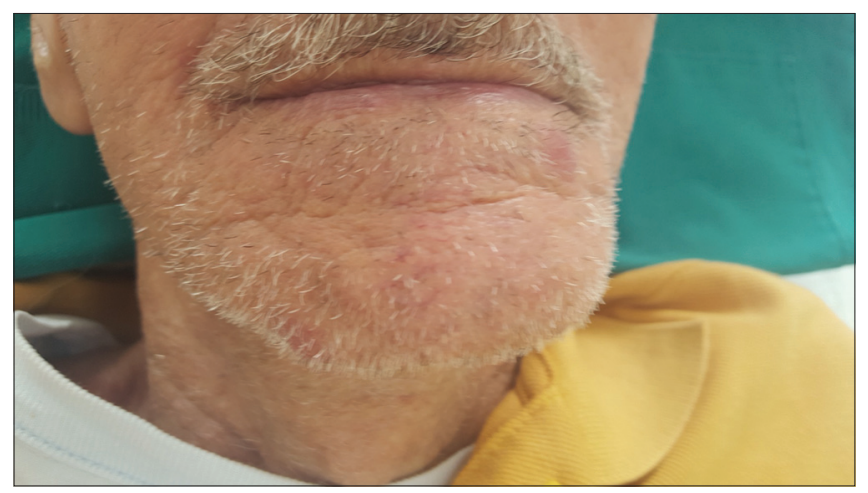

Figure 3: Clinic. Erythematous solid tumor of $1 \mathrm{~cm}$ in diameter on right side chin. Cachectic patient, without adenomegalias or other skin lesions.

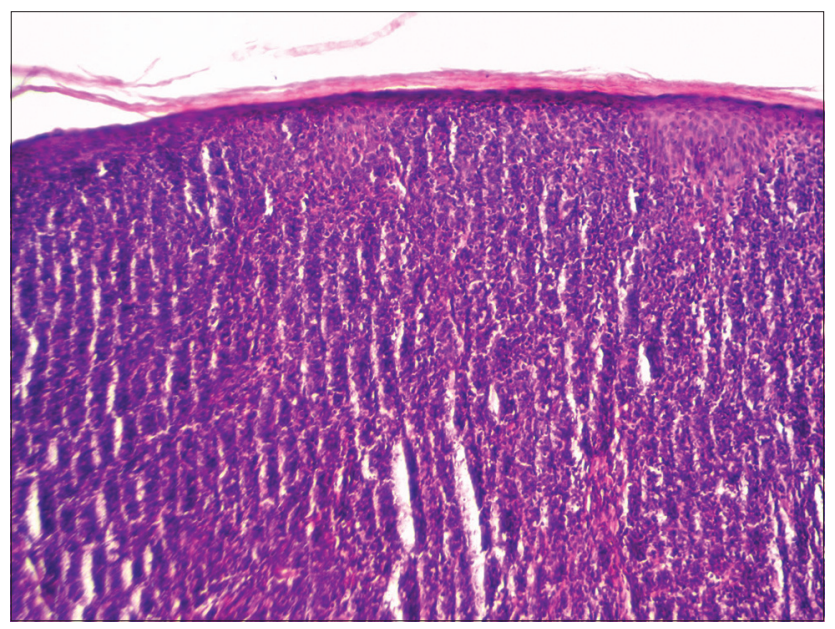

Figure 4: Histopathology. Neoplastic diffuse process settled in superficial and mid dermis. Absence of epidermal involvement or epidermotropism. The cell proliferation observed is of lymphoid strain and diffuse growth (HE 10X). 


\section{Inmunohistoquímica}

Las células linfoides son CD 20+, CD10-, MUM 1+, BCL 2+, BCL 6+/-.

\section{Laboratorio}

HMG: Gb 5.800/mm3, N 67\%, L 31\%, Eo 9\%, Hb $11,2 \mathrm{~g} / \mathrm{dl}$, Hto $35 \%$, Plaquetas 190000/mm3. Urea: 64 mg/dl; Creat 1,78 mg/dl; Perfil hepático, lipídico: En rango. VDRL y HIV No Reactivas. PAS total: $0,04 \mathrm{ng} / \mathrm{ml}$.

\section{Ecocardiografía}

FE: 65\%, dilatación de AI, Insuficiencia mitral y tricuspídea, Hipertensión pulmonar leve.

\section{Ecografía renal y vesico prostática}

Quiste renal simple lado izquierdo. Logia prostática de características normales sin signos de recidiva.

TAC con contraste de cuello, tórax, abdomen, pelvis

sin tumoraciones.

\section{Biopsia de Médula Ósea}

Fragmento de tejido óseo esponjoso con espículas óseas adelgazadas, notándose abundante tejido adiposo con tejido medular que muestran células de las tres líneas hematológicas. No se observan infiltración extrínseca.

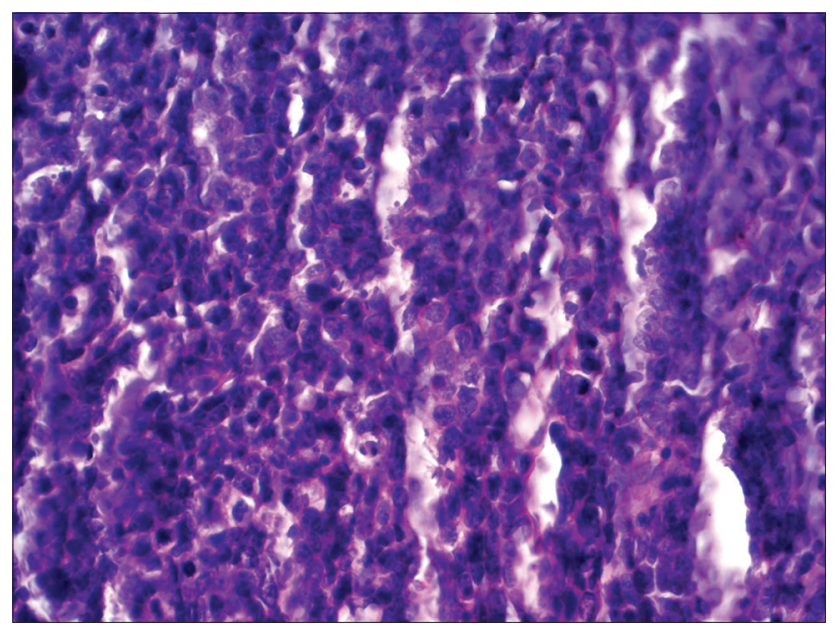

Figure 5: Histopathology. A higher magnification. Large cells with vesicular nuclei, one or more nucleoli and scarce cytoplasm. The mitotic index is high (HE 40X).

\section{Diagnóstico final}

Síndrome antifosfolipídico en paciente con artritis reumatoidea. Linfoma B Cutáneo Primario Difuso de Células Grandes, Tipo Pierna (PCDLBCL, leg type).

\section{Evolución y tratamiento}

El paciente tenía $50 \mathrm{~kg}$ de peso por lo que inició Rituximab $375 \mathrm{mg} / \mathrm{m} 2$, con etapa de inducción: Dosis de ataque $600 \mathrm{mg}$ cada 28 días por 6 dosis. Recibió las 6 sesiones con mejoría casi total de las lesiones cutáneas, pero fallece tras última sesión por complicaciones infecciosas.

Prior to the study, patient gave written consent to the examination and biopsy after having been informed about the procedure.

\section{COMENTARIOS}

Los linfomas cutáneos primarios se definen como tal cuando se originan en la piel sin evidencia de compromiso extracutáneo en el momento del diagnóstico. Pertenecen a los linfomas no Hodgkin extranodales, entre los cuales la piel es el segundo órgano más frecuentemente afectado luego del tracto gastrointestinal [1-3].

Los linfomas cutáneos de células B (LCCB) corresponden al 20-25\% de todos los linfomas cutáneos. En 2008, la WHO-EORTC define al linfoma cutáneo difuso de células grandes, tipo de la pierna como una entidad clínica aparte $[1,2]$.

Su etiopatogenia es desconocida. Se postula que puede representar una respuesta linfoproliferativa a un estímulo antigénico crónico del tejido linfoide asociado a la piel. Se desconocen los mecanismos implicados en la presencia o persistencia de estas células neoplásicas malignas en dermis; sólo en algunos casos se demostró presencia de agentes infecciosos tales como herpes virus tipo 8, VIH, VHC, bacterias como Borrelia Burgdorferi o en el contexto de enfermedades autoinmune $[1,2,4]$.

Afecta principalmente a pacientes mayores de 70 años, con predominio en mujeres 3-4:1 [1,3].

Clínicamente se presentan como nódulos o tumores eritematovioláceos, de consistencia firme, rápido crecimiento, localizado en una o ambas piernas, aunque también de manera infrecuente pueden asentar en 
otras regiones tales como cabeza, cuello, tronco y extremidades superiores $[1,4,5]$.

Los aspectos histopatológicos están dados por un infiltrado linfoide difuso, no epidermotropo, existiendo una zona de colágeno denominada zona de Grenz. El infiltrado corresponde a células grandes, con núcleo al menos 2 veces más grande que un linfocito pequeño, el cual puede extenderse hasta tejido celular subcutáneo $[2,4,6,7]$.

El estudio inmunohistoquímico pone de manifiesto células neoplásicas que expresan antígenos linfoides de células B (CD19, CD20, CD22, CD79 a). Asimismo, también el bcl6 puede ser positivo en la mayoría de los casos; el bcl2 es fuertemente positivo en los LCCB de células grande tipo pierna, lo que lo diferencia de otras localizaciones, donde su expresión es menor, mientras que el CD10 es negativo en la mayoría de los casos [2,4,6,7].

La tasa de supervivencia a los 5 años es de aproximadamente del 57-67\%; se reconoce como factor pronóstico, además del bcl2, a la localización anatómica, siendo menos agresivo cuando asienta en otro sitio fuera de la pierna, como nuestro caso [2,4,7-11].

El tratamiento recomendado incluye radioterapia, exéresis quirúrgica o la administración intralesional de quimioterápicos (cisplatino) para las lesiones únicas y poliquimioterapia con R-CHOP (rituximab, ciclosfosfamida, doxirubicina, vincristina $y$ prednisona) para las lesiones múltiples y cuando la progresión de la enfermedad es objetivada, podría plantearse el uso de monoterapia con rituximab (anticuerpo monoclonal anti-CD20), dependiendo cada caso en particular. El curso clínico es favorable, aunque ocasionalmente desarrollan recurrencias cutáneas [2,4,6,7-11].

En conclusión, presentamos este caso por tratarse de un linfoma cutáneo primario poco frecuente, constituyendo el primer caso en nuestro servicio, además de resaltar la buena evolución con quimioterapia única con Rituximab, teniendo en cuenta la edad de nuestro paciente y sus comorbilidades.

\section{Consent}

The examination of the patient was conducted according to the Declaration of Helsinki principles.

\section{BIBLIOGRAFÍA}

1. Martínez M, Meneses M, Vannetti A, Samper A, Martínez BernalM. Linfoma cutáneo primario de células B, tipo pierna: reporte de un caso. Arch Argent Dermatol. 2016;66:1-4.

2. Gallardo F, Pujol R. Diagnóstico y tratamiento de los linfomas cutáneos primarios de células B. Actas Dermosifiliogr 2004;95:537-47.

3. Azcune R, Barbarulo A, Gavazza S, Fontana MI, Spelta MG, Barrera M, et al. Linfomas B primitivos cutáneos: nuestra experiencia a propósito de 22 casos. Dermatol Argent. 2008;14:35-45.

4. Vilchez M, Villarreal M, Valente E, Ruiz Lascano A, Kurpis M. Linfoma primario cutáneo difuso de células B grandes, tipo pierna, localizado en tronco. Arch Argent Dermatol. 2010;60:1-4.

5. Campoy MV, Matamoros E, Michelena MA, Garritano MV, Maradeo R, Arena G, et al. Limfoma B primitivo cutáneo difuso de células grandes de la pierna localizado en antebrazo. Arch Argent Dermatol. 2015;65:86-9.

6. halid A, Wolfram S. Cutaneous Lymphoma. En: Wolff K, Goldsmith LA, Katz SI, Gilchrest BA, Paller AS, Leffell DJ. Fitzpatrick's Dermatology in General Medicine. $7^{\circ}$ Ed.; New York; Mc Graw Hill; 2008;3:1386-402.

7. García Herrera A, Estrach Panella T. Una visión de los linfomas cutáneos primarios de células B. Med Cut ILA. 2004;32:187-200.

8. Rodríguez Blanco I, Sánchez Aguilar D, Peteiro C, Toribio J. Linfoma B difuso de células grandes cutáneo en una pierna tras un linfoma testicular primario. Med Cut ILA. 2007;35:247-9.

9. Martín Carrasco P, Morillo Andújar M, Pérez Ruiz C, De Zulueta Dorado T, Cabrera Pérez R, Conejo-Mir J. Primary cutaneous B-cell lymphomas: study of 22 cases. Med Clin (Barc). 2016;147:207-10.

10. Kempf W, Kazakov D, Belousova I, Mitteldorf C, Kerl K. Paediatric cutaneous lymphomas: a review and comparison with adult counterparts. J Eur Acad Dermatol Venereol. 2015;29:1696-709.

11. Kempf W, Kazakov D, Mitteldorf C. Cutaneous Lymphomas: An Update. Part 2: B-Cell Lymphomas and Related Conditions. Am J Dermatopathol. 2014;36:197-210.

Copyright by Beatriz Di Martino Ortiz, et al. This is an open-access article distributed under the terms of the Creative Commons Attribution License, which permits unrestricted use, distribution, and reproduction in any medium, provided the original author and source are credited.

Source of Support: Nil, Conflict of Interest: None declared. 